\title{
Befundung von Urin-Protein-Mustern auf der Basis klinisch gesicherter Patientenkollektive. Typische Beispiele mit Textbefunden
}

\author{
Assessment of urinary-protein-pattern on the basis \\ of clinically characterized patients. Typical examples with reports
}

\author{
W. Hofmann', C. Sedlmeir-Hofmann', M. Ivandic', D. Schmidt', W. G. Guder', H. Edel' \\ 'Institut für Klinische Chemie, Städtisches Krankenhaus München-Bogenhausen \\ 2II. Medizinische Klinik, Städtisches Krankenhaus München-Harlaching
}

\begin{abstract}
Zusammenfassung:
Der Ausschluß und die Differenzierung von Proteinurien in prärenale, glomeruläre, tubulo-interstitielle und postrenale Formen ist durch Messung definierter Einzelproteine im Urin möglich. Glomeruläre Ursachen lassen sich von tubulo-interstitiellen Nephropathien am besten durch Vergleich der Albumin-mit der $\alpha_{1}$-Mikroglobulin-Ausscheidung unterscheiden. Aus dem Verhältnis IgG/Albumin ergeben sich bei Ausschluß tubulo-interstitieller oder postrenaler Ursachen Hinweise auf die Selektivität der glomerulären Basalmembran. Postrenale Proteinurien und Blutungen sind durch serumähnliche Pro-

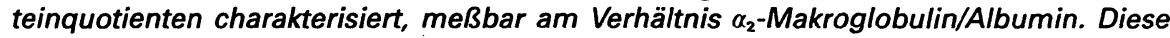
wechselseitige Abhängigkeit des Urinproteinmusters vom Grad der Albuminausscheidung läßt sich in Form von Quotienten, besser jedoch durch graphische Darstellung der Einzelkomponenten präsentieren. Ziel der vorliegenden Arbeit ist es, auf der Basis von Erfahrungen mit klinisch gesicherten Fällen an Hand von typischen Beispielen den Weg zur Befundung darzustellen. Diese Wissensbasis kann als Grundlage für eine rechnergestützte Befunderstellung dienen.
\end{abstract}

\section{Schlüsselwörter:}

Wissensbasis - Urineiweißdifferenzierung - $a_{1}$-Mikroglobulin - Albumin $-\lg G-a_{2}{ }^{-}$ Makroglobulin

\begin{abstract}
Summary:
Measuring defined proteins in urine specimens can exclude and differentiate prerenal, renal and postrenal types of proteinuria. By relating albumin excretion rates to those of $\alpha_{1}$-microglobulin, glomerular causes can be separated from tubulo-interstitial causes. The IgG/albumin ratio gives information about the selectivity of the glomerular ultrafiltration barrier, provided that a tubulo-interstitial or postrenal form of proteinuria is excluded. Postrenal types of proteinuria or bleedings are characterized by plasma-like protein ratios of $\alpha_{2}$-macroglobulin/albumin. These characteristic patterns of proteins dependent on the degree of albuminuria can be described by ratios or, even better, by graphic plots. The aim of this paper is to present data on proteinuria of clinically defined patients which form the basis for the interpretation of proteinuria results. This knowledge base can be used to assist urinary protein differentiation.
\end{abstract}

\section{Keywords:}

Knowledge base - urinary protein differentiation - $\alpha_{1}$-microglobulin - albumin - $\lg G$ $a_{2}$-macroglobulin

\section{Einleitung}

Die Urineiweißdifferenzierung stellt ein neues diagnostisches Verfahren dar, klinisch relevante Nierenparenchymerkrankungen mit bisher nicht erreichbarer diagnostischer Spezifität auszuschließen [1]. Gleichzeitig erlaubt die Analyse der Proteinmuster im Urin, verschiedene Erkrankungsformen der Niere als Ursachen der Proteinurie zu unterscheiden [2]. Mit den im Folgenden aufgeführten typischien Beispielen möchten wir die Komplexität der Befunderstellung für die Urineiweißdifferenzierung darstellen. Ziel unserer Bemühungen ist es außerdem, Befundtexte auf der Basis von Erfahrungen an klinisch exakt zugeordneten Patienten im Einzelfall wissensbasiert zu erstellen, um eine logisch nachvollziehbare, "einheitliche" Befundung zu erreichen. 


\section{Material und Methodik}

\section{Untersuchungsgut}

Patientenurine (2. Morgenurin) wurden ohne Zusätze in $10 \mathrm{ml}$-geschlossenen Polystyrolgefäßen (Greiner, Nürtingen) gesammelt und bis zur Abarbeitung bei $4^{\circ} \mathrm{C}$ im Kühlschrank gelagert (maximal zwei Tage). Bei allen Urinproben wurde eine automatisierte Teststreifenuntersuchung u.a. auf Blut, Leukozyten und Protein (Rapimat II, Behring, Marburg) durchgeführt. Vor Durchführung der Urinproteinuntersuchung wurden alle Urinproben 10 Minuten bei $800 \times g$ zentrifugiert.

Für die quantitative Bestimmung von Gesamteiweiß, $\alpha_{2}$ Makroglobulin, IgG, Albumin und $\alpha_{1}$-Mikroglobulin (Bestimmung in Serum und Urin) wurden turbidimetrische Verfahren auf einem herkömmlichen Analysenautomaten ausgearbeitet $[3,22]$. Kreatinin im Serum und Urin wurde konventionell nach einer kinetischen Jaffé-Methode durchgeführt [22]; die $\mathrm{N}$-acetyl- $\beta$-D-glucosaminidase-Bestimmung erfolgte nach Noto mit einem Testkit der Firma Boehringer Mannheim [22].

\section{Ergebnisse}

\section{Stufenweiser Aufbau der Wissensbasis zur Urineiweißdifferenzierung}

Der Befund als Ziel klinisch chemischer Diagnostik ist nach Abschluß der analytischen Bewertung eine wissens-

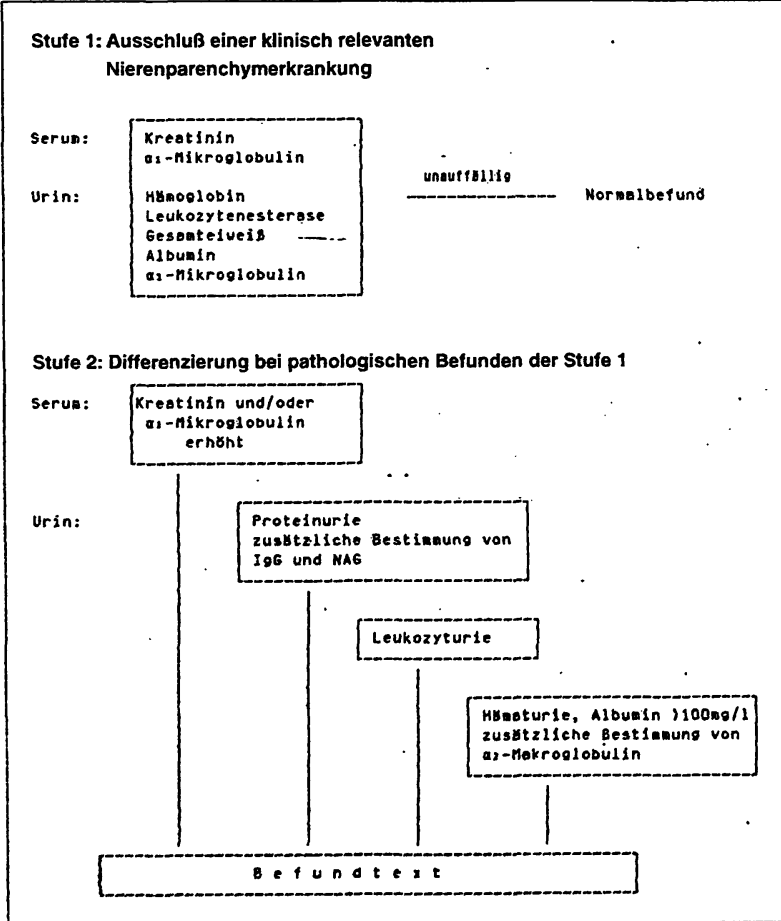

Abbildung 1: Stufenförmige Erstellung eines Befundtextes zur Urineiweißdifferenzierung. basierte Entscheidungsfindung, die stufenweise aus Einzelkomponeten erstellt und zu einem Gesamtbefund zusammengeführt wird (Abb. 1).

\section{Stufe 1: Ausschluß einer Nierenerkrankung}

Das Basisprogramm zur Urineiweißdifferenzierung besteht an unserer Klinik in der Bestimmung von Serumkreatinin, Serum- $\alpha_{1}$-Mikroglobulin [21] und den Urinmeßgrößen Leukozytenesterase, Hämoglobin, Gesamteiweiß, Albumin, $\alpha_{1}-$ Mikroglobulin und Kreatinin. In einem ersten Schritt werden die quantitativen Ergebnisse der Urinmeßgrößen auf Kreatinin umgerechnet und geprüft, ob die Ergebnisse außerhalb des jeweiligen Referenzbereiches liegen [1]. Die quantitativen Ergebnisse von Albumin und $\alpha_{1}$-Mikroglobulin werden in eine Graphik eingetragen (Abb. 2). Sind die Serum- und Urinmeßgrößen im Normalbereich, so ist eine klinisch relevante Nierenparenchymerkrankung mit großer Wahrscheinlichkeit ausgeschlossen [1].

\section{Typische Beispiele zur Urineiweißdifferenzierung}

Normalbefund (Abb. 2)

$\begin{array}{lll} & \text { Referenzbereich } & \text { Ergebnis } \\ \text { Serum: } & & \\ \text { Kreatinin } & \text { (bis } 1,2 \mathrm{mg} / \mathrm{dl}) & 0,5 \\ \alpha_{1}-\text { Mikroglobulin } & \text { (bis } 10,0 \mathrm{mg} / \mathrm{dl}) & 4,2\end{array}$

\section{Urin:}

Protein (Teststreifen)

Blut (Teststreifen)

Leukozytenesterase (Teststreifen')

negativ negativ negativ

Gesamteiweiß Albumin $a_{1}$-Mikroglobulin

(bis $100 \mathrm{mg} / \mathrm{g}$ Kreatinin) (bis $20 \mathrm{mg} / \mathrm{g}$ Kreatinin) 33 (bis $14 \mathrm{mg} / \mathrm{g}$ Kreatinin)

Beurteilung:

Aufgrund der Serumbefunde ist eine klinisch relevante Verminderung der glomerulären Filtrationsrate unwahr-

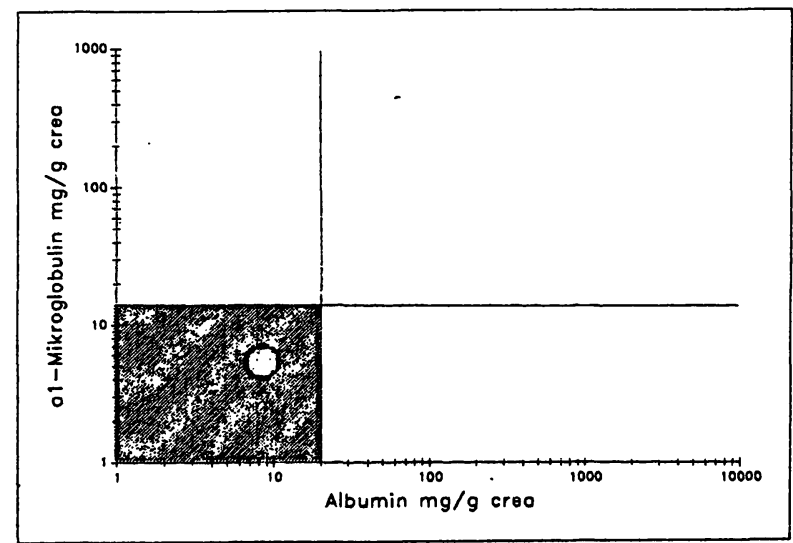

Abbildung 2: Der schraffierte Bereich stellt den Referenzbereich für Albumin (bis $20 \mathrm{mg} / \mathrm{g}$ Kreatinin) und $a_{1}$-Mikroglobulin (bis $14 \mathrm{mg} / \mathrm{g}$ Kreatinin) dar. 
scheinlich. Die Untersuchung der Urinmeßgrößen ergibt keinen Hinweis auf eine Störung der glomerulären Proteinfiltration und tubulären Reabsorption. Eine klinisch relevante Nierenparenchymerkrankung ist somit mit großer Wahrscheinlichkeit ausgeschlossen. Hinweise auf eine Blutung und/oder granulozytäre Entzündungsreaktion im Bereich der ableitenden Harnwege liegen nicht vor.

Stufe 2: Differenzierung:

Ist hingegen eine der Urinmeßgrößen oberhalb des Referenzbereiches, so werden für die Differenzierung der Proteinurie weitere Ergebnisse herangezogen:

ggf. IgG im Urin zur Beurteilung der Selektivität einer glomerulären Proteinurie,

ggf. $N$-acetyl- $\beta$-D-glucosaminidase (NAG) im Urin zur Differenzierung von Nierenerkrankungen mit vorwiegend tubulärer Proteinurie [19],

ggf. $\alpha_{2}$-Makroglobulin im Urin zur Differenzierung von Hämaturien (dreifach positivem Teststreifen auf Blut und Albumin über $100 \mathrm{mg} / \mathrm{l}[3]$ ).

\section{Stufe 2a: Serummeßgrößen}

Bei Erhöhung beider Serummeßgrößen (Kreatinin und $\alpha_{1}$-Mikroglobulin [21]) wird folgender Befundtext ausgegeben:

Es liegt eine Einschränkung der glomerulären Filtrationsrate vor.

An dieser Stelle kann durch Berücksichtigung von Alter, Geschlecht und Körpergewicht ein Hinweis auf das Ausmaß der Einschränkung der GFR erfolgen [4].

Ist nur eine der Serummeßgrößen erhöht, wird die Bestimmung der glomerulären Clearance empfohlen:

Zur Abklärung einer möglichen eingeschränkten Filtrationsrate wird die Untersuchung der glomerulären Clearance empfohlen.

Informationen über extrarenale Ursachen für Veränderungen von Kreatinin, z. B. Pseudokreatinine, erhöhte Muskelmasse und $\alpha_{1}$-Mikroglobulin, z.B. IgA-Plasmozytom (erhöht), Leberzirrhose (erniedrigt) werden bisher nicht berücksichtigt, können aber zusätzlich als Klartext in den abschließenden Befund eingegeben werden.

\section{Stufe 2b: Differenzierung der Proteinurie}

Prärenale Proteinurie

Liegt die Konzentration von Gesamteiweiß im Urin über $300 \mathrm{mg} / \mathrm{l}$ und die Summe aus der Albumin-, IgG- und $\alpha_{1}$ Mikroglobulinkonzentration unter $30 \%$ der Gesamteiweißausscheidung, so wird auf eine mögliche extrarenale Ursache der "Proteinlücke” hingewiesen [13]. Zusätzlich wird das Ausmaß der Proteinurie beschrieben und das Ausscheidungsmuster bewertet.

\section{Typische Beispiele zur Urineiweißdifferenzierung}

\section{Proteinurie}

1.0 Prärenale Proteinurie (Abb. 3). Bence Jones-Proteinurie bei monoklonaler Gammopathie IgG-Kappa; Immunfixation: Nachweis von freien Leichtketten Kappa im Urin:
Referenzbereich

Ergebnis

Urin:

Protein (Teststreifen)

schwach positiv

Blut (Teststreifen)

Leukozytenesterase (Teststreifen)

negativ

negativ

Gesamteiweiß

IgG

Albumin

$u_{1}$-Mikroglobulin

(bis $100 \mathrm{mg} / \mathrm{g}$ Kreatinin) (bis $10 \mathrm{mg} / \mathrm{g}$ Kreatinin)

1867

164 (bis $20 \mathrm{mg} / \mathrm{g}$ Kreatinin) (bis $14 \mathrm{mg} / \mathrm{g}$ Kreatinin)

93

80

$\left(\mathrm{Alb}+\lg \mathrm{G}+\alpha_{1}-\right.$ Mikroglobulin)/Gesamteiweiß IgG/Albumin

0,18

1,8

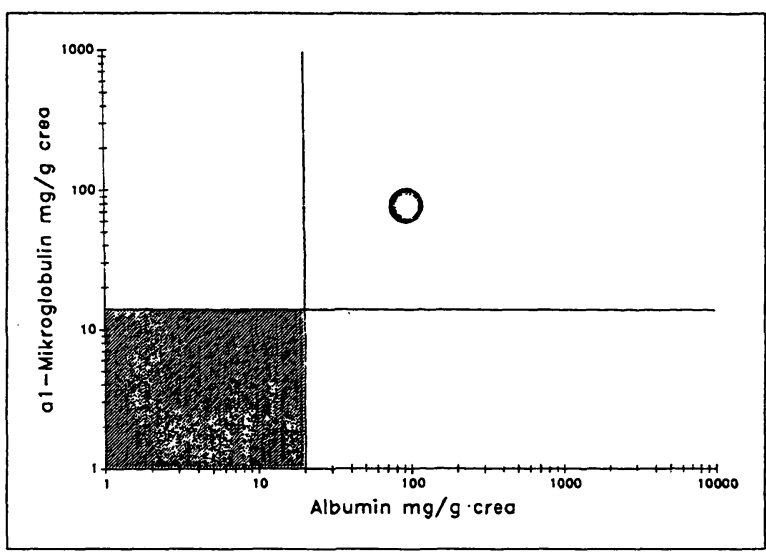

Abbildung 3: Bence-Jones-Proteinurie bei monoklonaler Gammopathie. Die deutliche tubuläre Komponente weist auf eine tubulointerstitielle Reabsorptionseinschränkung hin.

Beurteilung (Vorläufiger Befundtext nach der Urineiweißdifferenzierung):

Wegen des Mißverhältnisses der Summe der Albumin-, IgG- und $\alpha_{1}$-Mikroglobulinkonzentration zur Gesamteiweißkonzentration ((A/b+IgG $+a_{1}-$ Mikroglobulin)/Gesamteiweiß $<0,3)$ besteht der Verdacht auf eine prärenale Proteinurie. Zur Abklärung werden weitere Untersuchungen (SDS-Gradientengelelektrophorese, Immunfixation) durchgeführt. Endgültiger Befund erfolgt nach Abschluß dieser Untersuchungen. Es liegt eine gering erhöhte Ausscheidung von Albumin und IgG vor bei gleichzeitig deutlicher tubulärer Proteinurie. Die Befundkonstellation kann in erster Linie Hinweis auf eine tubulo-interstitielle Reabsorptionseinschränkung sein.

\section{Renale Proteinurie}

Basierend auf den Ausscheidungsmustern von Albumin und $\alpha_{1}$-Mikroglobulin (2) erfolgt die Zuordnung zu glomerulärén und tubulo-interstitiellen Nephropathien. Bei klarer Zuordnung erfolgt die Ausgabe einer der folgenden drei Texte:

Die Befundkonstellation ist vereinbar mit einer Glomerulopathie. 
Die Befundkonstellation ist vereinbar mit einer tubulo-interstitiellen Nephropathie.

Die Befundkonstellation ist vereinbar mit einer Glomerulopathie und einer tubulo-interstitellen Reabsorptionseinschränkung.

Bei tubulo-interstitieller Nephropathie entscheidet die Höhe der NAG-Aktivität ( $>15 \mathrm{U} / \mathrm{g}$ Kreatinin) über einen $\mathrm{Zu}$ satz: möglicherweise liegt eine akute Schädigung proximaler Tubuluszellen vor.

Nach Zuweisung zu einer der klinischen Diagnosegruppen erfolgt die Beschreibung des Ausmaßes der Proteinurie (Angaben in $\mathrm{mg} / \mathrm{g}$ Kreatinin):

glomerulär

Albumin

$$
\begin{gathered}
>20-<30 \\
30-100 \\
100-1000 \\
1000-3000 \\
>3000 \\
* \text { bei Erwachsenen }
\end{gathered}
$$

Ist die Zuordnung zu einer Glomerulopathie eindeutig, so wird in der Beschreibung der Albuminurie von glomerulärer Proteinurie gesprochen. Liegt hingegen eine tubulointerstitielle Nephropathie vor, so wird die erhöhte Albuminausscheidung als Albuminurie bezeichnet. Diese Differenzierung soll der Tatsache Rechnung tragen, daß die Albuminerhöhung im Harn bei tubulo-interstitieller $\mathrm{Ne}$ phropathie wahrscheinlich aus einer verminderten Reabsorption resultiert und somit nicht glomerulärer Genese ist.

Ist die Proteinurie glomerulär, so wird außerdem der Grad der Selektivität bewertet.

Bei Albumin $>500 \mathrm{mg} / \mathrm{g}$ Kreatinin und IgG/Albumin $<0,03$ sprechen wir von einer selektiv glomerulären Proteinurie, hingegen bei IgG/Albumin $>0,03$ von einer nichtselektiven glomerulären Proteinurie.

\section{Typische Beispiele zur Urineiweißdifferenzierung}

Proteinurie

2.0 Glomerulopathie

2.1 Minimal change Nephropathie (Abb. 4), histologisch gesichertes Rezidiv.

$$
\begin{aligned}
\text { Referenzbereich } & \begin{array}{l}
\text { Ergebnis } \\
\text { Rezidiv }
\end{array} \\
& \begin{array}{l}
\text { nach } \\
\text { Remission }
\end{array}
\end{aligned}
$$

\section{Serum:}

Kreatinin

(bis $1,2 \mathrm{mg} / \mathrm{dl}$ ) $\quad 1,0$

$a_{1}$-Mikroglobulin (bis $10,0 \mathrm{mg} / \mathrm{dl}$ ) $\quad 7,0$

Urin:

Protein (Teststreifen)

nicht bestimmt nicht bestimmt
Blut (Teststreifen)

Leukozyten-

esterase (Teststreifen)

Gesamteiweiß

$\lg G$

Albumin

$\alpha_{1}$-Mikroglob.

$$
\begin{aligned}
& \text { (bis } 100 \mathrm{mg} / \mathrm{g} \\
& \text { Kreatinin) }
\end{aligned}
$$

$$
\text { (bis } 10 \mathrm{mg} / \mathrm{g}
$$

Kreatinin)

(bis $20 \mathrm{mg} / \mathrm{g}$

Kreatinin)

(bis $14 \mathrm{mg} / \mathrm{g}$

Kreatinin)

$\left(\right.$ Alb $+\lg G+\alpha_{1}-$ Mikroglob.) $)$

Gesamteiweiß

lgG/Albumin

ca. 1

0,02

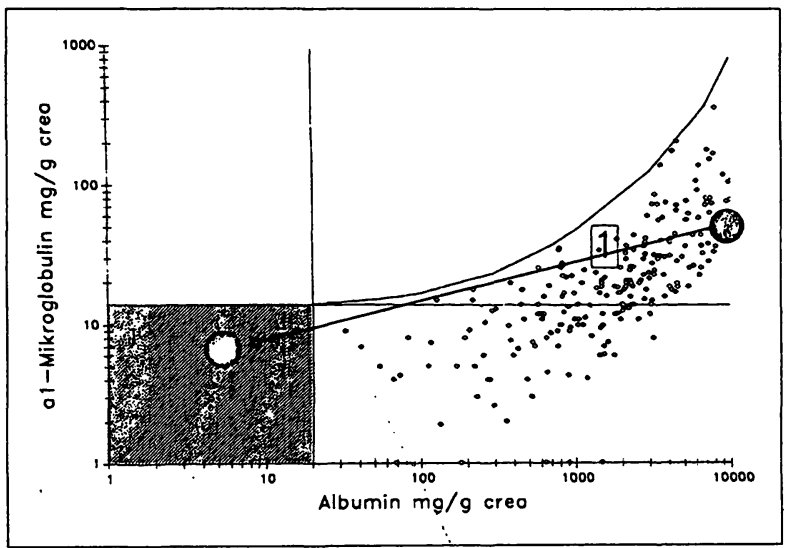

Abbildung 4: Minimal-change Nephropathie. Durch eine adäquate Corticoidtherapie wurde die Remission einer MinimalChange-Nephropathie erreicht. Bei 261 Patienten mit einer primären Glomerulopathie wurde eine Urineiweißdifferenzierung durchgeführt und die Konzentrationen für Albumin (Abszisse) und $\alpha_{1}$-Mikroglobulin (Ordinate) doppelt logarithmisch aufgetragen. Die obere Begrenzung kann durch eine Exponentialfunktion beschrieben werden. Die Fläche unterhalb der Begrenzungslinie wird mit 1 gekennzeichnet.

Beurteilung (Rezidiv):

Aufgrund der Serumbefunde ist eine klinisch relevante Verminderung der glomerulären Filtrationsrate unwahrscheinlich.

Beurteilung der Proteinurie:

Es liegt eine selektive, nephrotische glomeruläre Proteinurie vor, bei gleichzeitig geringer tubulärer Proteinurie. Die Befundkonstellation ist vereinbar mit einer Glomerulopathie. Gleichzeitig findet man bedingt durch die sehr hohe Albuminausscheidung (Proteinoverload) eine geringe tubulo-interstitielle Reabsorptionseinschränkung.

Beurteilung (Remission):

Aufgrund der Befundkonstellation ergibt sich kein Hinweis auf eine klinisch relevante Nierenparenchymerkrankung. 
2.2 IgA-Nephropathie (Abb. 5), fortgeschrittene mesangioproliferative Glomerulonephritis, histologisch gesichert.

\section{Referenzbereich}

Ergebnis

Serum:

Kreatinin

(bis $1,2 \mathrm{mg} / \mathrm{dl}$ )

$a_{1}$-Mikroglobulin

(bis $10,0 \mathrm{mg} / \mathrm{dl}$ )

\section{2,1}

21,6

Urin:

Protein (Teststreifen)

Blut (Teststreifen)

Leukozytenesterase (Teststreifen)

3fach positiv negativ negativ

Gesamteiweiß

IgG

(bis $100 \mathrm{mg} / \mathrm{g} \mathrm{Kreatinin)} 4096$

Albumin

(bis $10 \mathrm{mg} / \mathrm{g}$ Kreatinin) 326

(bis $20 \mathrm{mg} / \mathrm{g}$ Kreatinin) 2936

$\alpha_{1}$-Mikroglobulin

(bis $14 \mathrm{mg} / \mathrm{g}$ Kreatinin) 62

$\left(\mathrm{Alb}+\operatorname{lgG}+\alpha_{1}-\right.$ Mikroglobulin)/Gesamteiweiß $\quad 0,81$

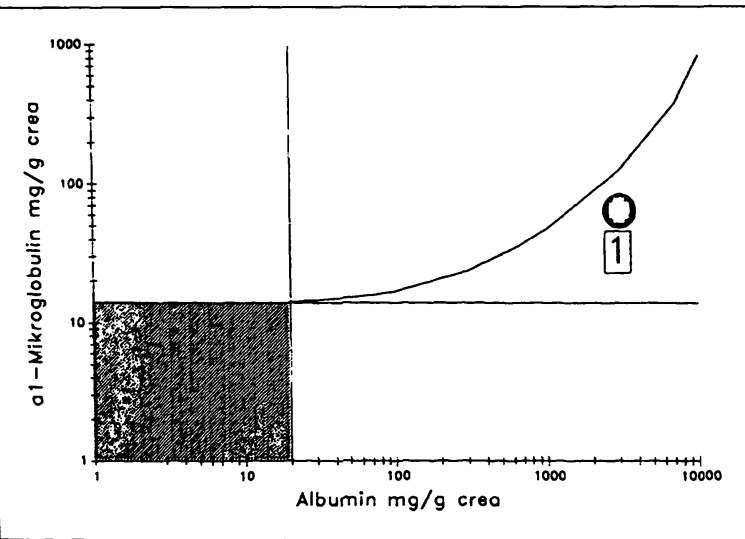

Abbildung 5: IgA-Nephropathie. Trägt man die Albumin-gegen die $a_{1}$-Mikroglobulinkonzentration auf, so liegt der Punkt innerhalb der Gruppe der primären Glomerulopathien (1) mit tubulointerstitieller Reabsorptionseinschränkung.

\section{Beurteilung:}

Es liegt eine Einschränkung der glomerulären Filtrationsrate vor.

Beurteilung der Proteinurie:

Es liegt eine nicht selektive, ausgeprägte glomeruläre Proteinurie vor, bei gleichzeitig deutlicher tubulärer Proteinurie. Die Befundkonstellation ist vereinbar mit einer Glomerulopathie und deutlicher tubulo-interstitieller Reabsorptionseinschränkung.

2.3 Diabetische Nephropathie (Abb. 6), Typ 1 Diabetiker, bei dem seit 11 Jahren ein Diabetes mellitus bekannt ist.

\section{Referenzbereich}

Ergebnis

Serum:

Kreatinin

$\alpha_{1}$-Mikroglobulin

(bis $1,2 \mathrm{mg} / \mathrm{dl}$ )

0,7

(bis $10,0 \mathrm{mg} / \mathrm{dl}$ )

11,8

Urin:

Protein (Teststreifen)

Blut (Teststreifen)

Leukozytenesterase (Teststreifen)

3fach positiv negativ negativ
Gesamteiweiß (bis $100 \mathrm{mg} / \mathrm{g}$ Kreatinin) 4936 $\lg G$

Albumin

$\alpha_{1}$-Mikroglobulin (bis $20 \mathrm{mg} / \mathrm{g}$ Kreatinin) 4106

(bis $14 \mathrm{mg} / \mathrm{g}$ Kreatinin) 25

$\left(\mathrm{Alb}+\operatorname{lgG}+\alpha_{1}\right.$-Mikroglobulin)/Gesamteiweiß $\quad 0,88$ IgG/Albumin

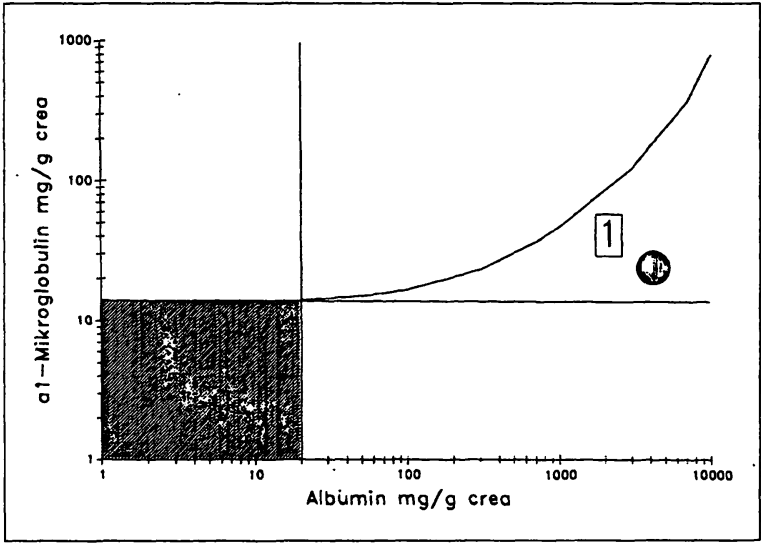

Abbildung 6: Diabetische Nephropathie (Stadium 4 nach Mogensen) [6]. Die Befundkonstellation von Albumin und $\alpha_{1}$-Mikroglobulin gibt den Hinweis auf eine Glomerulopathie mit geringer tubulo-interstitieller Reabsorptionseinschränkung. Liegen wie im vorliegenden Fall, klinische Angaben vor, kann sogar eine Zuordnung zu den von Mogensen eingeführten Stadien der diabetischen Nephropathie vorgenommen werden.

Beurteilung:

Zur Abklärung einer möglichen eingeschränkten Filtrationsrate wird die Untersuchung der glomerulären Clearance empfohlen.

Beurteilung der Proteinurie:

Es liegt eine nicht selektive, nephrotisch-glomeruläre Proteinurie vor, bei gleichzeitig geringer tubulärer Proteinurie. Die Befundkonstellation ist vereinbar mit einer Glomerulopathie und geringer tubulo-interstitieller Reabsorptionseinschränkung.

Kommentar: Bei glomerulären Proteinurien im Grenzbereich (Albumin $<30 \mathrm{mg} / \mathrm{g}$ Kreatinin) ohne tubuläre Proteinurie sollte man besser von einer glomerulären Permeabilitätsstörung und nicht schon von einer Glomerulopathie sprechen. 

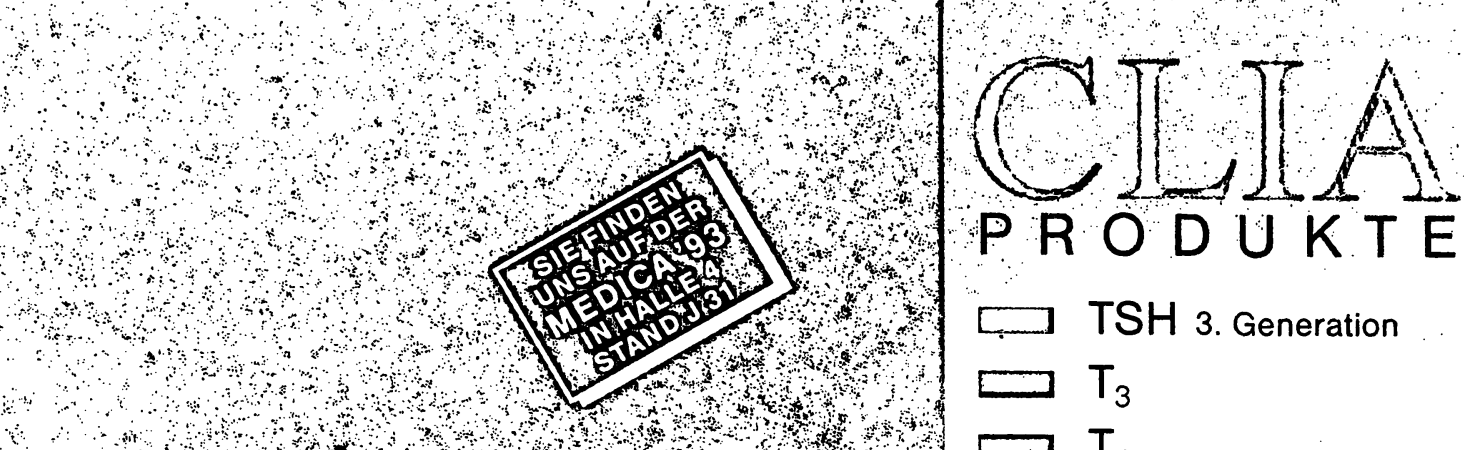

$\square \mathrm{TSH}$ 3. Generation

$\square \mathrm{T}_{3}$

$\square \mathrm{T}_{4}$

$\square \mathrm{FT}_{3}$

$\longrightarrow \mathrm{FT}_{4}$

Anti TPO

Anti TG

PTH intakt

$y$

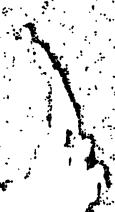

$\mathrm{HGH}$

Ferritin

FSH

if

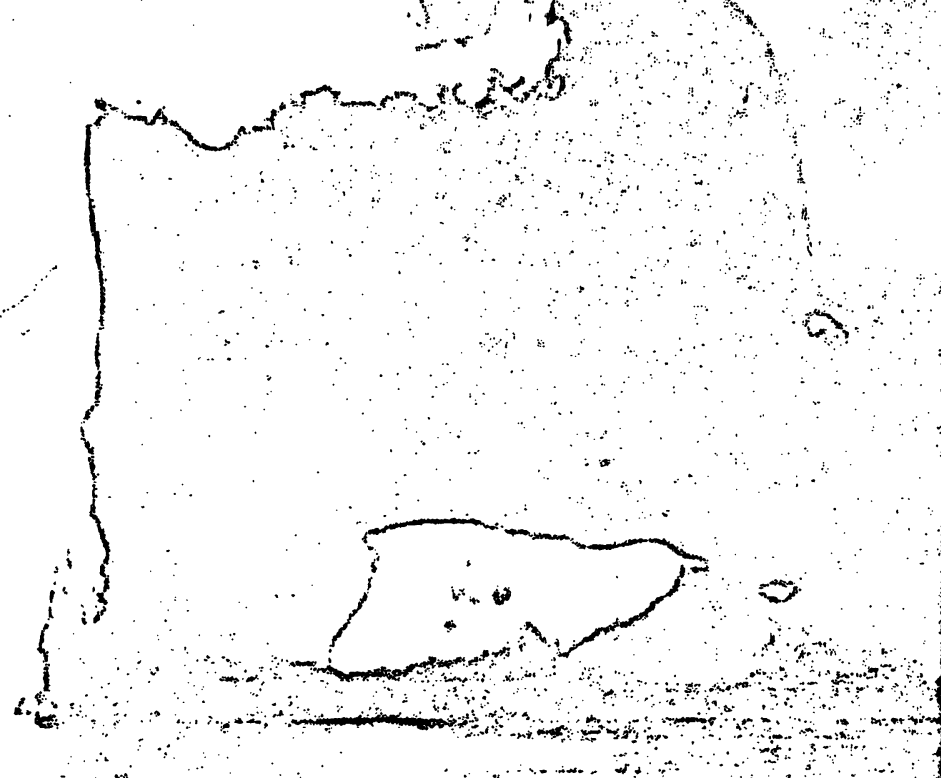

0

Nichols Institute

Diagnostika GmbH

Dieselstrasse 18

D-61231 Bad Nauheim

Tel 06032 - 9106-0

Fax 06032 - 910621

Inr Service-Partner Schweiz:

Nichols Institute

Diagnostics S.A.

45 A, Route des Acacias

1227 Les Acaclas/Geneva,

Tel $(022) 3429840$
Fax $(022) 3429848$

$=-15$ 


\section{HAMBURGER SYMPOSIUM ÜBER TUMORMARKER \\ 5. bis 8. Dezember 1993}

\section{Aktuelle Tumordiagnostik Möglichkeiten - Klinische Relevanz - Forschung - Perspektiven}

Internationaler Erfahrungsaustausch - Internationaler Workshop

Tagungsleitung und Organisation

Prof. Dr. R. Klapdor

Medizinische Universitätsklinik, Martinistraße 52, 20251 Hamburg,

Tel. (0 40) 4717 - 2944 oder 36 08, Fax: (0 40) 4717 - 5145.

Tagungsort/Location:

Hotel Elysee, Rothenbaumchaussee 10, Hamburg 13,

Am Dammtorbahnhof, Tel. (0 40) 4141 20, Fax: (0 40) 41412733

Programmübersicht

Sonntag/Sunday

Saal Europa

$9.30-12.30$

Workshop 1:

18 Jahre CA $19-9$ und CA 125

18 Years CA $19-9$ und CA 125

Spiegelsaal

$14.00-14.15$

Begrüßung/Welcome

$14.15-15.45$

Gastroenterologie 1/Gastroenterology I

15.45-16.15 Poster - Kaffeepause/Coffee Break

$16.15-17.15$

Gynäkologie //Gynecology I

$17.15-18.30$

Gynäkologie II/Gynecology II

Montag/Monday

Spiegelsaal

$8.30-9.30$

Lunge $1 /$ Lung I

$9.30-10.30$

Lunge II/Lung $\|$

10.30 - 11.00 POSTER - Kaffeepause/Coffee Break

$11.00-12.00$

Onkogene, Zytokine, Rezeptoren I/Oncogenes, Cytokines,

Receptors I

$12.00-13.00$

Onkogene, Zytokine, Rezeptoren II/Oncogenes, Cytokines,

Receptors II

12.30 - 14.00 Mittagspause/Lunch-POSTER

$14.00-15.00$

Immunhistochemie I/Immunohistochemistry I

$15.00-16.00$

Immunhistochemie II/Immunohistochemistry II

16.15 - 18.30

Workshof II:

Gentechnologie in Diagnostik und Therapie/Gentechnology in Biagno-

sis and Therapie

Saal Europa

$8.30-9.30$

$9.30-10.30$
$10.30-12.30$

Gastroenterology II/Gastroenterology II „Baltic Session“

$14.00-15.00$

Verschiedenes Naria

$15.00-16.00$

Gynäkologie III/Gynecology III

$16.15-18.30$

Workshop III:

Immunosuppression/-defizienz (Transplantation/AIDS) und Krebs/

Immunosuppression/-deficiency (Transplantation and Cancer)

\section{Dienstag/Tuesday}

Spiegelsaal

$8.30-9.30$

Urogenital Trakt IUrogenital Tract I

10.30 - 11.00 POSTER - Kaffeepause/Coffee Break

$11.00-12.00$

Immunszintigraphie I//mmunoscintigraphy |

$12.00-13.00$

Immunszintigraphie II/Immunoscintigraphy II

13.00 - 14.00 Mittgaspause Lunch - POSTER

$14.00-15.00$

Therapie I/Therapy I

$15.00-16.00$

Therapie II/Therapy II

15.45 - 16.15 POSTER - Kafeepause/Coffee Break

$16.15-18.45$

Satelliten-Symposium: Lungen-Karzinom/Lung Cancer

Mittwoch/Wednesday

Spiegelsaal

$8.30-9.30$

Neue Assays 1/New Assays I

$9.30-10.30 \quad \ldots$

Neue Assays II/New Assays II

10.30 - 10.45 POSTER - Kaffeepause/Coffee Break

$10.45-11.45$

Qualitätskontrolle und Standardisierung I/Quality Control and Standardization I

$11.45-12.45$

Qualitätskontrolle und Standardisierung I/Quality Control and Standardization I

$12.50 \mathrm{Uhr}$

Verleịhung der Poster-Preise

Endè der Tagung/Closing remarks

Asien-Saal

$13.30-17.00$

Arbeitsgruppe Qualitätskontrolle und Standardisierung

Working Group Quality control and standardization 
Grenzwertige Erhöhungen findet man u.a. bei schlecht eingestellten Diabetikern [23], Hypertonikern und nach weitgehender Remission einer glomerulären Erkrankung.

\subsection{Interstitielle Nephropathie}

3.1 Interstitielle Nephropathie (Abb. 7) durch Analgetikaund Laxantien-Abusus

\section{Serum:}

Referenzbereich

Ergebnis

Kreatinin

(bis $1,2 \mathrm{mg} / \mathrm{dl}$ )

$a_{1}$-Mikroglobulin

(bis $10,0 \mathrm{mg} / \mathrm{dl}$ )

\section{3,0}

18,0

Urin:

Protein (Teststreifen)

Blut (Teststreifen)

Leukozytenesterase (Teststreifen)

negativ

negativ

negativ

\section{Gesamteiweiß}

$\lg G$

Albumin

$\alpha_{1}$-Mikroglobulin

NAG

(bis $100 \mathrm{mg} / \mathrm{g}$ Kreatinin) 1486

(bis $10 \mathrm{mg} / \mathrm{g}$ Kreatinin) 157

(bis $20 \mathrm{mg} / \mathrm{g}$ Kreatinin) 181

(bis $14 \mathrm{mg} / \mathrm{g}$ Kreatinin) 575

(bis $5 \mathrm{U} / \mathrm{g}$ Kreatinin) 20

$\left(\mathrm{Alb}+\lg \mathrm{g}+\alpha_{1}\right.$-Mikroglob.)/Gesamteiweiß

0,61

IgG/Albumin

0,87

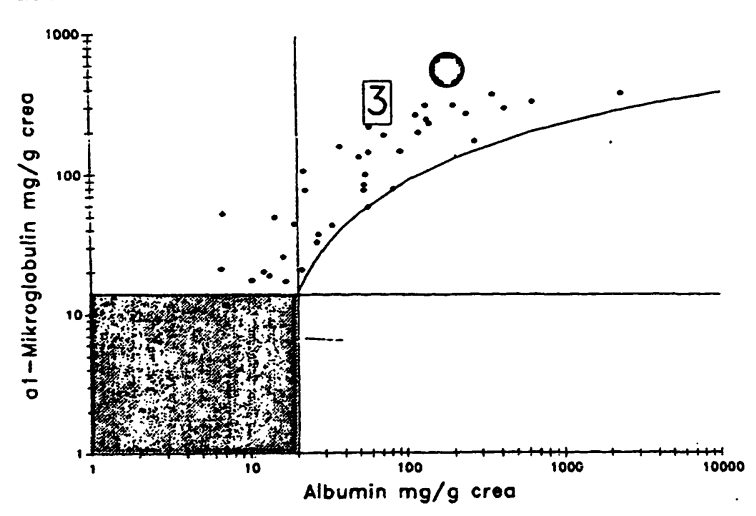

Abbildung 7: Interstitielle Nephropathie. Bei 57 Patienten mit einer gesicherten (klinisch bzw. histologisch) interstitiellen $\mathrm{Ne}$ phropathie konnte das Kollektiv durch eine logarithmische Kurve nach unten begrenzt werden (Bereich 3). Für das Beispiel liegt der erhaltene Punkt oberhalb dieser Kurve und kann somit eindeutig als tubulo-interstitielle Nephropathie identifiziert werden.

Beurteilung:

Es liegt eine Einschränkung der glomerulären Filtrationsrate vor.

Beurteilung der Proteinurie:

Es liegt eine deutlich erhöhte Ausscheidung von Albumin und IgG vor, bei gleichzeitig ausgeprägter tubulärer Proteinurie. Die Befundkonstellation ist vereinbar mit einer tubulo-interstitiellen Nephropathie (möglicherweise liegt eine akute Schädigung proximaler Tubuluszellen vor).

3.2 Akute Abstoßungsreaktion nach Nierentransplantation (Abb. 8)

Serum:

Kreatinin

Referenzbereich

Ergebnis

$\alpha_{1}$-Mikroglobulin

(bis $1,2 \mathrm{mg} / \mathrm{dl}$ )

3,2

(bis $10,0 \mathrm{mg} / \mathrm{dl}$ )

21,0

Urin:

Protein (Teststreifen)

Blut (Teststreifen)

Leukozytenesterase (Teststreifen)

negativ

negativ

negativ

Gesamteiweiß

$\lg G$

Albumin

$\alpha_{1}$-Mikroglobulin

NAG

(bis $100 \mathrm{mg} / \mathrm{g}$ Kreatinin) 113

(bis $10 \mathrm{mg} / \mathrm{g}$ Kreatinin) 35

(bis $20 \mathrm{mg} / \mathrm{g}$ Kreatinin) 36

(bis $14 \mathrm{mg} / \mathrm{g}$ Kreatinin) 75

(bis $5 \mathrm{U} / \mathrm{g}$ Kreatinin) $\quad 25$

(Alb $+\operatorname{lgG}+\alpha_{1}$-Mikroglob.)/Gesamteiweiß $\quad>1,0$ IgG/Albumin

0,97

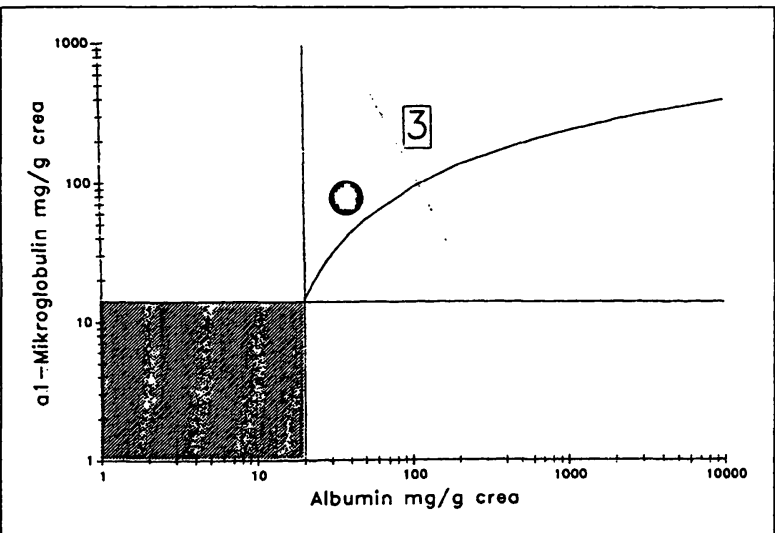

Abbildung 8: Akute Abstoßung nach Nierentransplantation. Das Ausscheidungsmuster weist auf eine tubulo-interstitielle Nephropathie hin. Die deutlich erhöhte NAG-Ausscheidung weist auf eine mögliche akute Schädigung proximaler Tubuluszellen hin.

Beurteilung:

Es liegt eine Einschränkung der glomerulären Filtrationsrate vor.

Beurteilung der Proteinurie:

Es liegt eine deutlich tubuläre Proteinurie bei geringgradig erhöhter Ausscheidung von Albumin und IgG vor. Der Befund ist vereinbar mit einer tubulo-interstitiellen Nephropathie. Möglicherweise liegt eine akute Schädigung proximaler Tubuluszellen vor.

Kommentar: Bei tubulären Proteinurien im Grenzbereich ( $\alpha_{1}-$ Mikroglobulin $<20 \mathrm{mg} / \mathrm{g}$ Kreatinin) ohne glomeruläre .

Lab.med. 17: 507 (1993) 
Proteinurie sollte man besser von einer tubulären Dysfunktion und nicht von einer tubulo-interstitiellen Nephropathie sprechen.

Grenzwertige Erhöhungen findet man u.a. bei metabolisch schlecht eingestellten Patienten mit Diabetes mellitus [24] und unter tubulotoxischer Medikation, 2. B. Aminoglycoside, Amphotericin etc.

4.0 Überlappungsbereich Glomerulopathie-tubulo-interstitielle Nephropathie

4.1 Nephrosklerose (Abb. 9), histologisch gesichert

Serum:

Kreatinin

Referenzbereich

Ergebnis

(bis $1,2 \mathrm{mg} / \mathrm{dl}$ )

$a,-$ Mikroglobulin

(bis $10,0 \mathrm{mg} / \mathrm{dl}$ )

4,3

25,0

Urin:

Protein (Teststreifen)

Blut (Teststreifen)

Leukozytenesterase (Teststreifen)

negativ

negativ

negativ

Gesamteiweiß

$\lg G$

Albumin

$a_{1}$-Mikroglobulin

(bis $100 \mathrm{mg} / \mathrm{g}$ Kreatinin) 409

(bis $10 \mathrm{mg} / \mathrm{g}$ Kreatinin) 62

(bis $20 \mathrm{mg} / \mathrm{g}$ Kreatinin) 218

(bis $14 \mathrm{mg} / \mathrm{g}$ Kreatinin) 72

(Alb $+\lg G+\alpha_{1}-$ Mikroglob.)/Gesamteiweiß

0,86

IgG/Albumin

0,28

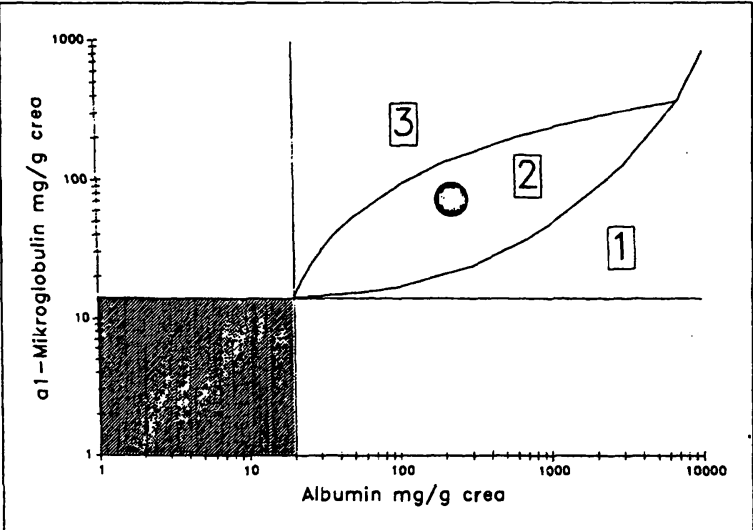

Abbildung 9: Nephrosklerose. Das im vorliegenden Fall gefundene Ausscheidungsmuster liegt im Überlappungsbereich glomerulärer und tubulo-interstitieller Erkrankungen. Die deutliche tubuläre Komponente weist auf eine tubulo-interstitielle Reabsorptionseinschränkung bei gleichzeitig glomerulärer Funktionsstörung hin. Das Überwiegen der einen oder anderen Komponente sollte im Text zum Ausdruck kommen.

Bei Befundkonstellationen im Überlappungsbereich soll durch den Befundtext zum Ausdruck gebracht werden, daß man auf die Pathogenese in diesem Fall nicht rückschließen kann.
Beurteilung:

Es liegt eine Einschränkung der glomerulären Filtrationsrate vor.

Beurteilung der Proteinurie:

Es liegt eine deutlich erhöhte Ausscheidung von Albumin und IgG vor, bei gleichzeitig deutlicher tubulärer Proteinurie. Der Befund ist u.a. vereinbar mit einer Glomerulopathie mit tubulo-interstitieller Reabsorptionseinschränkung oder aber einer interstitiellen Nephropathie mit sekundärer Glomerulopathie.

4.2 Diabetische Nephropathie (Abb. 10), Typ 1 Diabetiker, bei dem vor 4,5 Jahren ein Diabetes mellitus diagnostiziert wurde.

Referenzbereich

Ergebnis

Serum:

Kreatinin

$\alpha_{1}$-Mikroglobulin

(bis $1,2 \mathrm{mg} / \mathrm{dl}$ )

0,8

(bis $10,0 \mathrm{mg} / \mathrm{dl}$ )

4,3

Urin:

Protein (Teststreifen)

Blut (Teststreifen)

Leukozytenesterase (Teststreifen)

negativ negativ negativ

Gesamteiweiß

$\lg G$

Albumin

$\alpha_{1}$-Mikroglobulin

(bis $100 \mathrm{mg} / \mathrm{g}$ Kreatinin) 173

(bis $10 \mathrm{mg} / \mathrm{g}$ Kreatinin) 27

(bis $20 \mathrm{mg} / \mathrm{g}$ Kreatinin) 116

(bis $14 \mathrm{mg} / \mathrm{g}$ Kreatinin) 24

(Alb $+\operatorname{lgG}+\alpha_{1}-$ Mikroglob.)/Gesamteiweiß $\quad 0,96$ IgG/Albumin

\section{0,23}

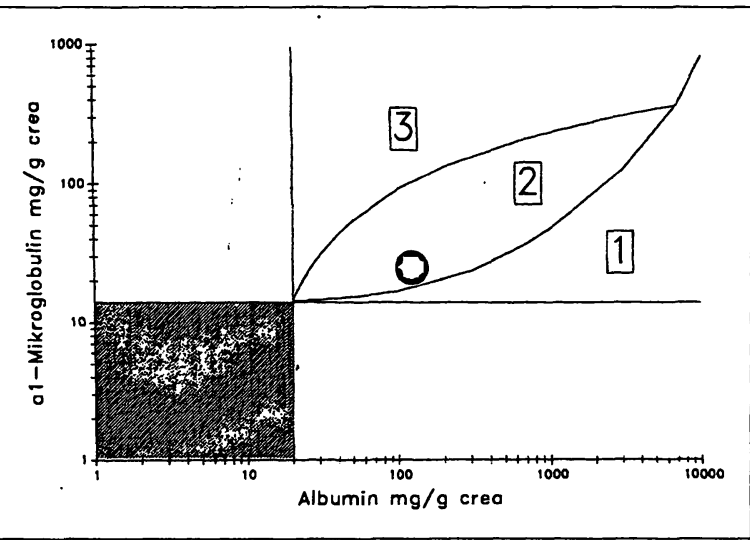

Abbildung 10: Diabetische Nephropathie (Stadium 3 nach Mogensen). Für dieses Beispiel erlaubt die Albumin- und $\alpha_{1}$ Mikroglobulinkonzentration im Urin ohne klinische Angaben keine eindeutige Zuordung. Durch die zusätzliche Information, daß der untersuchte Urin von einem Typ 1 Diabetiker stammt, kann der Befundtext entsprechend abgefaßt werden.

Liegt der gefundene Punkt im Überlappungsbereich und sind keine weiteren klinischen Angaben vorhanden, so faßt der "Überlappungstext" beide pathophysiologischen Konstellationen zusammen. Liegen weitere klinische In- 
formationen vor, wie Diabetes mellitus, arterielle Hypertonie etc., so.kann der Textbefund entsprechend abgefaßt werden.

Ähnliche Wertekonstellationen wie oben aufgeführt, waren bei weiteren Diabetikern im Stadium 3 der diabetischen Nephropathie nachweisbar [23].

Beurteilung:

Aufgrund der Serumbefunde ist eine klinisch relevante Verminderung der glomerulären Filtrationsrate unwahrscheinlich.

Beurteilung der Proteinurie:

Es liegt eine deutlich erhöhte Ausscheidung von Albumin und IgG vor, bei gleichzeitig grenzwertiger tubulärer Proteinurie. Der Befund ist u.a. vereinbar mit einer Glomerulopathie bei Diabetes mellitus.

\section{Stufe 2c: Differenzierung einer Leukozyturie}

Liefert der Teststreifen auf Leukozytenesterase ein positives Ergebnis und liegen Gesamteiweiß, Albumin und $\alpha_{1}$ Mikroglobulin im Referenzbereich, so wird im Textbefund auf eine mögliche postrenale Entzündung hingewiesen:

Der Nachweis von Leukozytenesterase weist auf eine mögliche postrenale Entzündung hin. Die Untersuchung der Urinmeßgrößen ergibt aber keinen Hinweis auf Störung der glomerulären Proteinfiltration und tubulären Proteinreabsorption. Eine klinisch relevante Nierenparenchymerkrankung ist mit großer Wahrscheinlichkeit ausgeschlossen.

Diskrepanzen zwischen dem Ergebnis des Teststreifentestes und der Sedimentuntersuchung werden bisher nicht berücksichtigt.

Liegt hingegen eine geringe Albuminurie bei Leukozyturie vor,

Albumin

Gesamteiweiß

30-100 mg/g Kreatinin

$\alpha_{1}$-Mikroglobulin

$\leq 150 \mathrm{mg} / \mathrm{g}$ Kreatinin

$\leq 14 \mathrm{mg} / \mathrm{g}$ Kreatinin

so lautet der Textbefund:

Die Urineiweißdifferenzierung sollte nach Abklingen der Leukozyturie wiederholt werden, da auch Entzündungen im Bereich der ableitenden Harnwege mit geringen Albumin- und/oder lgG-Erhöhung èinhergehen können.

Bei deutlichen Proteinurien

Albumin $\quad>100 \mathrm{mg} / \mathrm{g}$ Kreatinin und

Gesamteiweiß $>150 \mathrm{mg} / \mathrm{g}$ Kreatinin und/oder

$\alpha_{1}$-Mikroglobulin $>14 \mathrm{mg} / \mathrm{g}$ Kreatinin

wird neben der Proteinuriedifferenzierung auf mögliche postrenale Proteinbeimengungen im Rahmen einer Entzündung im Bereich der ableitenden Harnwege hingewiesen:

- Ein entsprechender Befundtext zur Differenzierung der Proteinurie wird eingefügt -

Beurteilung der Leukozyturie:

Zur Abschätzung des Ausmaßes der renalen Beteiligung bei Entzündungen im Bereich der ableitenden Harnwege sollte die Urineiweißdifferenzierung nach Abklingen der Leukozyturie wiederholt werden.

Typische Beispiele zur Urineiweißdifferenzierung Leukozyturie (Abb. 11): Patient mit gesicherter Pyelonephritis:

$\begin{array}{lll} & \text { Referenzbereich } & \text { Erge } \\ \text { Kerum: } & & \\ \text { Kreatinin } & \text { (bis } 1,2 \mathrm{mg} / \mathrm{dl} \text { ) } & 1,0 \\ \alpha_{1} \text {-Mikroglobulin } & \text { (bis } 10,0 \mathrm{mg} / \mathrm{dl}) & 10,7\end{array}$

Urin:

Protein (Teststreifen)

Blut (Teststreifen)

Leukozytenesterase (Teststreifen)

schwach positiv negativ

3fach positiv

Gesamteiweiß

$\lg G$

Albumin

$\alpha_{1}$-Mikroglobulin

NAG

(bis $100 \mathrm{mg} / \mathrm{g}$ Kreatinin) 1100

(bis $10 \mathrm{mg} / \mathrm{g}$ Kreatinin) 149

(bis $20 \mathrm{mg} / \mathrm{g}$ Kreatinin) 188

(bis $14 \mathrm{mg} / \mathrm{g}$ Kreatinin) 188

(bis $5 \mathrm{U} / \mathrm{g}$ Kreatinin) $\quad 14$

(Alb $+\lg G+\alpha_{1}-$ Mikroglob.)/Gesamteiweiß $\quad 0,48$

lgG/Albumin

0,79

Befundtext:

Zur Abklärung einer möglichen eingeschränkten Filtrationsrate wird die Untersuchung der glomerulären Cléarance empfohlen.

Beurteilung der Proteinurie:

Es liegt eine deutlich erhöhte Ausscheidung von Albumin und IgG vor, bei gleichzeitig ausgeprägter tubulärer Proteinurie. Die Befundkonstellation ist vereinbar mit einer tubulo-interstitiellen Nephropathie.

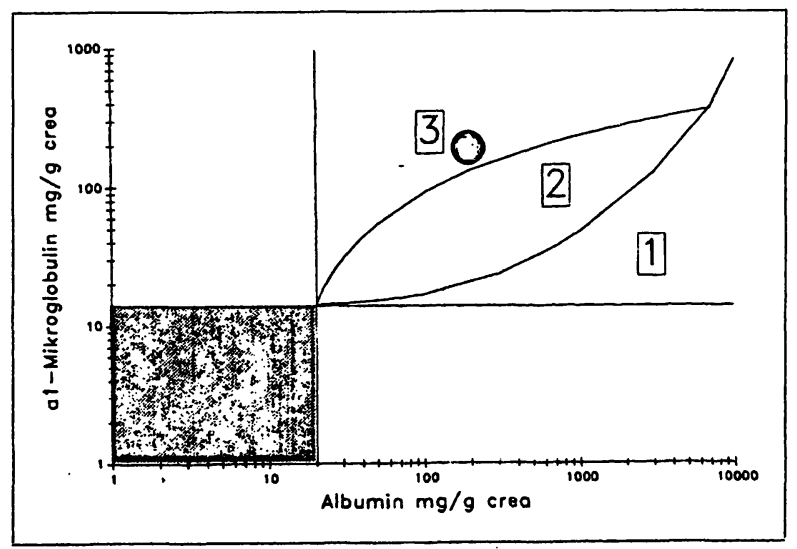

Abbildung 11: Pyelonephritis. Das gefundene Ausscheidungsmuster ist typisch für eine tubulo-interstitielle Nephropathie. Die orhöhte NAG-Ausscheidung legt die Vermutung nahe, daß es sich hierbei um eine zusätzliche akute Schädigung proximaler Tubuluszellen handelt. 
Beurteilung der Leukozyturie:

Es liegt cine Leukozyturie vor, bei Hinweis auf eine tubulointerstitielle Nephropathio.

Zur Abschätzung des Ausmaßes der renalen Beteiligung bei Entzündungen sollte die Urineiweißdifferenzierung nach Abklingen der Leukozyturie wiederholt werden.

\section{Stufe 2d: Differenzierung einer Hämaturie}

Liegt ein positives Teststreifenergebnis für Hämoglobin vor, so lassen sich prärenale, renale und postrenale Ursachen der Hämaturie unterscheiden. Die prärenalen Ursachen "Myoglobinurie" und "Hämoglobinurie" werden durch die Regeln zur prärenalen Proteinurie (Stufe 2a) abgefangen. Renale und postrenale Ursachen ergeben typische Proteinmuster, wenn bei einem dreifach positiven Hämoglobinteststreifen die Albuminausscheidung 100 $\mathrm{mg} / \mathrm{l}$ überschreitet [3]. Bei einer Albuminausscheidung unter $100 \mathrm{mg} / \mathrm{l}$ ist eine Differenzierung durch die Einzelproteinbestimmung nicht möglich [2, 3]. In diesem Fall wird folgender Text ausgegeben:

Die Differenzierung der renalen von der postrenalen Hämaturie ist bei einer Albuminausscheidung unter 100 $\mathrm{mg} / \mathrm{l}$ mit der Proteinanalytik nicht möglich. Die Phasenkontrastmikroskopie...

Hier folgt je nach Ergebnis der mikroskopischen Untersuchung ein Befundtext.

Ist die Albuminausscheidung größer als $100 \mathrm{mg} / \mathrm{l}$ (Teststreifen für Hämoglobin dreifach positiv), so erfolgt die Differenzierung der Hämaturie auf der Basis unterschiedlicher Quotienten von IgG, $\alpha_{2}$-Makroglobulin und $\alpha_{1}$-Mikroglobulin zu Albumin [3].

Tabelle 2: Entscheidungskriterien zur Hämaturiedifferenzierung.

\begin{tabular}{llll}
\hline Textbefund: & $\mathbf{1}$ & $\mathbf{2}$ & $\mathbf{3}$ \\
\hline IgG/Albumin & $>0,2$ & $<0,2$ & $>0,2$ \\
$u_{2}$-Makroglobulin/Albumin & $>0,02$ & $<0,02$ & $<0,02$ \\
$\alpha_{1}$-Mikroglobulin/Albumin & $<1,0$ & $<1,0$ & $>1,0$ \\
\hline
\end{tabular}

Textbefund:

1. Es liegt mit großer Wahrscheinlichkeit eine postrenale Hämaturie vor.

Kontrolle nach Abklingen der Hämaturie empfohlen.

2. Es liegt mit großer Wahrscheinlichkeit eine renale (glomeruläre) Hämaturie vor, eine zusätzliche Blutbeimengung aus postrenalen Quellen kann nicht ausgeschlossen werden.

Zusätzlich wird die Proteinurie bewertet.

3. Es liegt mit großer Wahrscheinlichkeit eine renale (tubulo-interstitielle) Hämaturie vor, eine zusätzliche geringe postrenale Blutbeimengung kann nicht ausgeschlossen werden.

Zusätzlich wird die Proteinurie bewertet.

Typische Beispiele zur Urineiweißdifferenzierung

Hämaturie:

1. Postrenale Hämaturie bei Harnleiterstein.
Referenzbereich

Ergebnis

Serum:

Kreatinin

$a_{1}$-Mikroglobulin

(bis $1,2 \mathrm{mg} / \mathrm{dl}$ )

1,1

(bis $10,0 \mathrm{mg} / \mathrm{dl}$ )

2,6

Urin:

Protein (Teststreifen)

Blut (Teststreifen)

Leukozytenesterase (Teststreifen)

positiv

3fach positiv

negativ

Gesamteiweiß

$u_{2}$-Makroglobulin

$\lg G$

Albumin

$\alpha_{2}$-Mikroglobulin

(bis $100 \mathrm{mg} / \mathrm{g}$ Kreatinin) 1099

(bis $10 \mathrm{mg} / \mathrm{g}$ Kreatinin) $\quad 15,3$

(bis $10 \mathrm{mg} / \mathrm{g}$ Kreatinin) 91,5

(bis $20 \mathrm{mg} / \mathrm{g}$ Kreatinin) 363

(bis $14 \mathrm{mg} / \mathrm{g}$ Kreatinin) $\quad 7,6$

(Alb $+\operatorname{lgG}+a_{1}$-Mikroglob.)/Gesamteiweiß $\quad 0,42$

IgG/Albumin

0,25

$a_{2}$-Makroglobulin/Albumin

0,04

$\alpha_{1}$-Mikroglobulin/Albumin

0,02

Befundtext:

Aufgrund der Serumbefunde ist eine klinisch relevante Verminderung der glomerulären Filtrationsrate unwahrscheinlich.

Beurteilung der Hämaturie:

Es liegt mit großer Wahrscheinlichkeit eine postrenale $\left(\alpha_{2}-\right.$ Makroglobulin/A/bumin >0,02, Ig G/Albumin >0,20) Hämaturie vor, zwischen renalen und postrenal ausgeschiedenen Proteinen kann nicht unterschieden werden. Kontrolle nach Abklingen der Hämaturie empfohlen.

2. Renale (glomeruläre) Hämaturie (Abb.12) bei extrakapillärer Glomerulonephritis

\section{Serum:}

Referenzbereich

Ergebnis

Kreatinin

$a_{1}$-Mikroglobulin

(bis $1,2 \mathrm{mg} / \mathrm{dl}$ )

(bis $10,0 \mathrm{mg} / \mathrm{dl}$ )

2,0

17,6

Urin:

Protein (Teststreifen)

Blut (Teststreifen) ..

Leukozytenesterase (Teststreifen)

3fach positiv

3fach positiv negativ

Gesamteiweiß

$\alpha_{2}$-Makroglobulin

IgG

Albumin

$a_{1}$-Mikroglobulin

(bis $100 \mathrm{mg} / \mathrm{g}$ Kreatinin) 6790

(bis $10 \mathrm{mg} / \mathrm{g}$ Kreatinin) 32,0

(bis $10 \mathrm{mg} / \mathrm{g}$ Kreatinin) $\quad 413,3$

(bis $20 \mathrm{mg} / \mathrm{g}$ Kreatinin) $\quad 5245$

(bis $14 \mathrm{mg} / \mathrm{g}$ Kreatinin) 79,5

$\left(\right.$ Alb $+\operatorname{lgG}+\alpha_{1}-$ Mikroglob.)/Gesamteiweiß $\quad 0,84$

IgG/Albumin

$a_{2}$-Makroglobulin/Albumin

0,08

$a_{1}$-Mikroglobulin/Albumin

0,006

0,01

Befundtext:

Es liegt eine Einschränkung der glomerulären Filtrationsrate vor. 


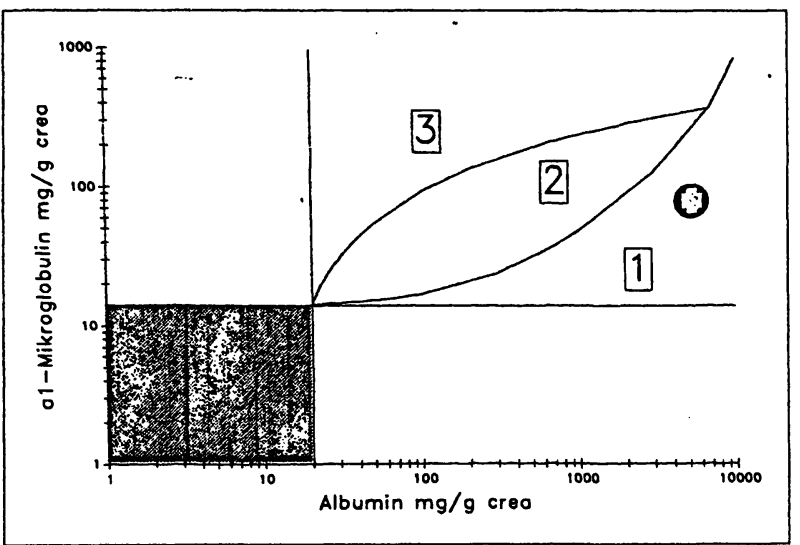

Abbildung 12: Renale Hämaturie. Der $\alpha_{2}$-Makroglobulin/AlbuminQuotient weist auf eine mögliche renale Hämaturie hin. Gleichzeitig läßt das Ausscheidungsmuster für Albumin und $\alpha_{1}-$ Mikroglobulin differentialdiagnostisch an eine Glomerulopathie mit deutlicher tubulo-interstitieller Reabsorptionseinschränkung denken.

Beurteilung der Proteinurie:

Es liegt eine nicht selektive, nephrotische glomeruläre Proteinurie vor, bei gleichzeitig mäßiger tubulärer Proteinurie.

Die Befundkonstellation ist vereinbar mit einer Glomerulopathie. Gleichzeitig findet man eine deutliche tubulo-interstitielle Reabsorptionseinschränkung.

Beurteilung der Hämaturie:

Es liegt mit großer. Wahrscheinlichkeite eine renale (glomeruläre) Hämaturie ( $\alpha_{2}$-Makroglobulin/Albumin $<0,02$, IgG/Albumin $<0,20$ ) vor, eine zusätzliche Blutbeimengung aus postrenalen Quellen kann nicht ausgeschlossen werden.

\section{Diskussion}

Wie Untersuchungen der letzten Jahre gezeigt haben [1], ist für den Ausschluß einer akuten Nierenerkrankung eine begrenzte Zahl spezifischer Untersuchungen (Leukozytenesterase, Hämoglobinpseudoperoxidase, Albumin, $\alpha_{1}-$ Mikroglobulin, Gesamteiweiß, Serumkreatinin) besser geeignet als der "traditionelle Harnstatus" [1, 5]. Als empfindlicher Parameter zur Erfassung glomerulärer Dysfunktionen hat sich die Albuminbestimmung durchgesetzt [6, 7]. Wie wir in den letzten Jahren vor allem durch morphometrische Arbeiten von Bohle $[8,9]$ gelernt haben, scheint nicht das Ausmaß des glomerulären Schadens die Prognose der Nierenerkrankung zu bestimmen, sondern die tubulo-interstitielle Fibrose. Als Ausdruck dieses irreversiblen Umbaus [10] findet man sekundär eine progressive Abnahme der glomerulären Filtrationsleistung [11]. In Folge dieses Funktionsverlustes werden zusätzlich kleinmolekulare Proteine wie $\alpha_{1}$-Mikroglobulin oder $\beta_{2}$-Mikroglobulin vermehrt mit dem Urin ausgeschieden [12]. Die Messung dieser Proteine erlaubt somit, funktionelle Änderungen schon sehr früh zu erfassen. Weber et al. [12] weisen darauf hin, daß $\alpha_{1}$-Mikroglobulin, als im Urin stabiles und einfach zu messendes Mikroprotein, den Funktionsverlust widerspiegelt. Bei Serumkreatininkonzentrationen über $2 \mathrm{mg} / \mathrm{dl}$ (glomeruläre Filtrationsrate $<50 \mathrm{ml} / \mathrm{min}$ ) findet man häufig als Ausdruck der verminderten tubulointerstitiellen Resorptionsfläche eine erhöhte Ausscheidung von $\alpha_{1}$-Mikroglobulin. Prärenale Proteinurien (z.B. Bence-Jones-Proteinurien) weisen, wie von Boege [13] gezeigt, häufig eine "Lücke" zwischen Gesamteiweiß und der Summe der Konzentrationen für Albumin, IgG und $\alpha_{1}-$ Mikroglobulin auf. Diagnostisch kann dies ein erster Hinweis auf eine Bence-Jones-Proteinurie sein. Die Frühdiagnostik ist von pathophysiologischer Relevanz, da freie Leichtketten tubulotoxisch wirken können [14]. Die sekundäre tubulo-interstitielle Insuffizienz wird deutlich durch das typische "tubulo-interstitielle" Ausscheidungsmuster von $\alpha_{1}$-Mikroglobulin zu Albumin bzw. IgG zu Albumin.

Die "Minimal-change Nephropathie", als behandelbare Glomerulopathie, zeigt ein charakteristisches Ausscheidungsmuster. Bei meist nephrotischer Gesamteiweißausscheidung liegt der Albuminanteil in der Regel über $90 \%$ der Gesamteiweißausscheidung. Der niedrige Quotient aus IgG und Albumin weist auf die hohe Selektivität der Proteinurie hin $[15,16]$. Die im vorliegenden Fall geringe tubuläre Proteinurie (erhöhtes $\alpha_{1}$-Mikroglobulin) ist wahrscheinlich durch die hohe Proteinbelastung (Protein overload) im proximalen Tubulus bedingt. Tierexperimentelle Untersuchungen von Bernard et al. bestätigen unsere Vermuturig [25], daß die tubuläre Reabsorption von Proteinen sättigbar ist und bei Überschreiten dieser Schwellenkonzentration immer eine kleinmolekulare Proteinurie zu finden ist. Bei einer Albuminausscheidung über $3000 \mathrm{mg} /$ g Kreatinin fanden wir in allen Patientenurinen als Zeichen dieser "Überlaufproteinurie" eine erhöhte $\alpha_{1}$-Mikroglobulinausscheidung. Die Histologie des beschriebenen Einzelfalls ergab bei der Minimal-change Nephropathie (Rezidiv), wie auch in der Literatur beschrieben, keine tubulointerstitielle Mitreaktion [17].

Ist die Glomerulopathie bereits weit fortgeschritten, so finden wir z. B. bei einem Patienten mit einer IgA-Nephropathie neben der deutlichen Proteinurie histologisch auch eine tubulo-interstitielle Fibrose und im Urin als Korrelat eine hohe Konzentration an $\alpha_{7}$-Mikroglobulin.

Bei einem Patienten mit Diabetes mellitus (Typ I, seit mindestens 11 Jahren bekannt) fanden wir bei der Urineiweißdifferenzierung eine im nephrotischen Bereich liegende Eiweißausscheidung. Gleichzeitig weist die gering erhöhte Ausscheidung von $\alpha_{1}$-Mikroglobulin auf eine geringe tubulo-interstitielle Resorptionseinschränkung hin. Nach Mogensen [24] liegt eine diabetische Nephropathie Stadium 4 vor. Die quantitative Analyse des Proteinmusters erlaubt, über das von diesen Autoren gegebene Schema hinaus, eine Abschätzung der tubulo-interstitiellen Läsion und den Ausschluß nicht diabetischer Ursachen der Albuminurie [23].

Im Gegensatz zu den Glomerulopathien zeigen die tubulointerstitiellen Nephropathien ein deutlich anderes Ausscheidungsmuster mit Überwiegen des tubulären Markerproteins $\alpha_{1}$-Mikroglobulin. Diese Formen der Nephropathie sind also eindeutig von Glomerulopathien zu unterscheiden. Hierbei weist eine mäßig erhöhte Aktivität der NAG eher auf einen chronischen Prozeß hin, wohingegen ein deutlicher Anstieg (> $15 \mathrm{U} / \mathrm{l}$ ) auf eine akute Schädigung .

Lab.med. 17: 511 (1993) 
proximaler Tubuluszellen hinweisen kann (z.B. nephrotoxische Medikamente). Diese Differenzierung ist weder durch Teststreifen noch durch die Gesamteiweißbestimmung möglich.

In dem von uns untersuchten Krankengut fanden wir häufig ältere Patienten mit einer geringgradigen Proteinurie (negativer Teststreifen auf Protein!), bei eingeschränkter GFR. Das Auscheidungsmuster weist in diesem Fall eher auf einen leichten glomerulären Schaden mit deutlicher tubulo-interstitieller Insuffizienz hin (ischämische Nephropathien (Nephrosklerose)). Da aber auch progrediente tubulo-interstitielle Nephropathien zu einer sekundären Glomerulopathie führen können, ist eine Unterscheidung zwischen einer fortgeschrittenen Glomerulopathie und einer tubulo-interstitiellen Nephropathie mit sekundärer glomerulärer Mitbeteiligung im Überlappungsbereich nicht immer möglich. Der Textbefund stellt daher für diese Konstellation eine Kombination dar und läßt beide Möglichkeiten zu. Bei einem weiteren Patienten mit Diabetes mellitus (Typ 1), aber im Gegensatz zu obigen Patienten einer Erkrankungsdauer von 4,5 Jahren, war das Ausmaß der Proteinurie deutlich geringer. Die grenzwertige Ausscheidung von $\alpha_{1}$-Mikroglobulin weist auf eine geringe funktionelle Störung proximaler Tubuluszellen hin [23]. Nach Mogensen [24] liegt ein Stadium 3 der diabetischen Nephropathie vor. Bei positivem Teststreifentest auf Leukozytenesterase und dem typischen Ausscheidungsmuster für eine akute tubulo-interstitielle Nephropathie (deutliche $\sigma$-Mikroglobulin- und NAG-Erhöhung, 20) liegt der Verdacht nahe, daß hier ein Entzündungsprozeß im Niereninterstitium vorliegen könnte. Findet sich keine tubuläre Proteinurie, so muß man bedenken, daß Albuminund auch lgG-Erhöhungen im Rahmen von unteren Harnwegsentzündungen (postrenale Proteinurie) vorkommen können [18]. Die Differenzierung der Hämaturie in renale und postrenale Ursachen ist bei urologisch/nephrologischen Patienten eine häufige Fragestellung. Gerade hier können nichtinvasive Verfahren zu einer Abnahme der Belastung (Zystoskopie) für den Patienten und auch zu einer Kostenreduktion führen. Postrenale Hämaturien (mit dreifach positivem Teststreifen auf Hämoglobin, Albuminausscheidung größer $100 \mathrm{mg} / \mathrm{l}$ ) können durch einen $\alpha_{2}$-Makroglobulin/Albumin-Quotienten $>0,02$ von renalen Formen unterschieden werden [2, 3]. In Zweifelsfällen kann die Phasenkontrastmikroskopie weitere Aufschlüsse über die Ursache der Hämaturie geben. Für den Fall der extrakapillären Glomerulonephritis weist der niedrige $\alpha_{2}$-Makroglobulin/Albumin-Quotientèn $(<0,02)$ auf die glomeruläre $\mathrm{Ge}$ nese der Hämaturie hin. Eine zusätzliche Blutbeimengung aus postrenalen Quellen kann nicht ausgeschlossen werden.

Wie die hier dargestellten Beispiele zeigen sollen, ist die Interpretation der Urineiweißdifferenzierung komplex. Sie können nicht alle Möglichkeiten abdecken, erscheinen uns aber exemplarisch und stellen einen ersten Versuch für eine einheitliche Befundung dar. Für die Zukunft erscheint uns ein rechnergestütztes Verfahren [26] ein sinnvolles Hilfsmittel für die Interpretation durch den Experten.
Literatur:

1. Hofmann, W. (1991) Diagnostic strategies for exclusion and differemiation of proteinuria, leukocyturia and haematuria. Wiener $\mathrm{Kiin}$. Wochenschr. 103 (Suppl. 189). 16-20.

2. Hofmann, W., Rossmüller, B., Guder, W. G., Edel, H. (1992) A new strategy for characterizing proteinuria and haematuria from single pattern of defined proteins in urine. Eur. J. Clin. Chem. Clin. Biochem. 30, 707-712.

3. Hofmann. W., Schmidt, D., Guder, W. G., Edel. H. (1991) Differentation of hematuria by quantitative determination of urinary marker proteins. Klin. Wochenschr. 69, 68-75.

4. Cockroft. D., Gault, M. H. (1976) Predictive value of kreatinine clearance from serum kreatinine. Nephron 16, 13-20.

5. Regenbogen, C. (1993) Vergleichende Darstellung etablierter und neuer Verfahren zum AusschluB einer klinisch relevanten Nierenparenchymerkrankung. Dissertation, München.

6. Mogensen, C. E. (1987) Microalbuminuria as a predictor of clinical diabetic nephropathy. Kidney Int. 31, 673-689.

7. Deckert, T., Feldt-Rasmussen, B., Djurup, R., Deckert, M. (1988) Glomerular size and charge selectivity in insulin-dependent diabetes mellitus. Kidney Int. 33, 100-106.

8. Bohle, A., Gise, H. V., Mackensen, Haen-S. (1981) The obliteration of the postglomerular capillaries and its influence upon the function of both glomeruli and tubuli. Klin. Wochenschr. 59, 1043-1051.

9. Bohle, A. Mackensen, Haen-S., Gise, H. (1991) The consequence of tubulointerstitial changes for renal function in glomerulonephritis, in: Americo. A., Cortelli P., Massry, S. E. (eds): Tubulo-Interstitial nephropathies. Boston, Dordrecht, London, Kluwer, pp 29-40.

10. Kuncio, G. S., Neilson, E. G., Averty, T. (1991) Mechanisms of tubulointerstitial fibrosis, Kidney Int. 39, 550-556.

11. Schainuk, L. I., Strikere, G. E., Cutler, R. E. (1970) Structural-functional correlations in renal disease. Part II: The correlations. Hum. Pathol. 1, $631-640$.

12. Weber, M. H., Verwiebe, R. (1992) $a_{1}$-Microglobulin (Protein HC): Features of a promising indicator of proximal tubular dysfunction. Eur. J. Clin. Chem. Clin. Biochem. 30, 683-691.

13. Boege, F., Koehler, B., Liebermann, F., Luther, A. (1990) Identification and quantification of Bence-Jones proteinuria by automated nephelometric screening. J. Clin. Chem. Clin. Biochem. 28, 37-42.

14. Cooper, E. H., Forbes, M. A., Crockson, R. A., Mac Lennan, I. C. M. (1984) Proximal renal tubular function in myelomatosis. Observations in the fourth Medical Research Council. Trial J. Clin. Pathol. 37, 852-858.

15. Cameron, J. S., Blandford, G. (1966) The simple assessment of selectivity in heavy proteinuria. Lancet II, 242-247.

16. Boesken, W. H. (1977) Die SDS-PAA-Elektrophorese der Urinproteine: Eine Methode zur Differentialdiagnose der Nephropathien und zur Analyse extrarenaler Proteinurien. Urologe 17, 140-144.

17. Saito, T., Atkins, R. C. (1990) Contribution of mononuclear leukocytes to the progression of experimenteal focal glomerular sclerosis. Kidney Int. 37. 1076-1083.

18. Lehn, P. (1991) Diagnostische Aussagekraft quantitativer UrinmeßgrōBen im Vergleich zum Teststreifen bei Bakteriurie, Dissertation, München. 19. Price, R. G. (1992) Measurement of $N$-acetyl- $\beta, D$-glucosaminidase and its isoenzymes in urine: Methods and clinical applications. Eur. J. Clin. Chem. Clin. Biochem. 30, 693-7058.

20. Sandberg. T., Cooper, E. H., Lidin-Janson, G., Yu, H. (1985) Fever and proximal tubular function in acute pyelonephritis. Nephron 41, 39-44.

21. Yu, H., Yanagisava, Y., Forbes, M. A., Cooper, E. H., Crockson, R. A., Mac Lennan, I. C. M. (1983) Alpha-1-microglobulin: an indicator protein for renal tubular function. J. Clin. Pathol. 36, 253-259.

22. Hofmann, W., Guder, W. G. A. (1989) diagnostic programme for quantitative analysis of proteinuria. J. Clin. Chem. Clin. Biochem. 27, 589-600.

23. Hofmann, W., Palicek, I., Guder, W. G., Renner, R., Hepp, K. D. (1993) Consideration of the biological variation in interpreting elevated $\mathrm{lgG}, a_{1}$ microglobulin and $\mathrm{N}$-acetyl- $\beta$-D-glucosaminidase (NAG) excretion in urine of patients with type 1 diabetes. in Vorbereitung.

24. Mogensen, C. E. (1987) Microalbuminuria as a predictor of clinical diabetic nephropathy. Kidney Int. 31, 673-689.

25. Bernard, A. (1988) The renal uptake of proteins: A nonselective process in conscious rats. Kidney Int. 34, 175-185.

26. Schröder, J. P., Pohl, B., Trendelenburg, Ch. (1993) Zum Einsatz von wissensbasierten Systemen im Bereich der Laboratoriumsmedizin, GIT LaborMedizin 16, 239-245.

\section{Anschrift für die Autoren:}

Dr. W. Hofmann, Prof. Dr. W. G. Guder

Institut für Klinische Chemie

Städtisches Krankenhaus München-Bogenhausen

Englschalkingerstr. 77

D-81925 München 


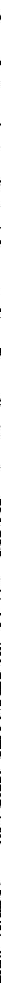

\section{MIT KOMFORT ZUM ZIEL}

Das Leben angenehmer zu gestalten, ist das Ziel vieler technischer Entwicklungen.

Einen Beweis dafür liefert Ihnen unser ECOM 6122. Dieses handliche, leistungsstarke

Photometer für die Klinische Chemie übernimmt das Mischen, Inkubieren und Messen.

100 Methoden-Speicherplätze, größtenteils änderbar programmiert, stehen dafür zur

Verfügung. Und die komfortable Bedienerführung sowie der automatische Filterwechsel

und das Temperieren auf 25, 30 oder

$37^{\circ} \mathrm{C}$ mit Peltiertechnik garantieren

einfachstes Handling. Alles

kleine und mittlere Labore

oder Backup-Gerät.

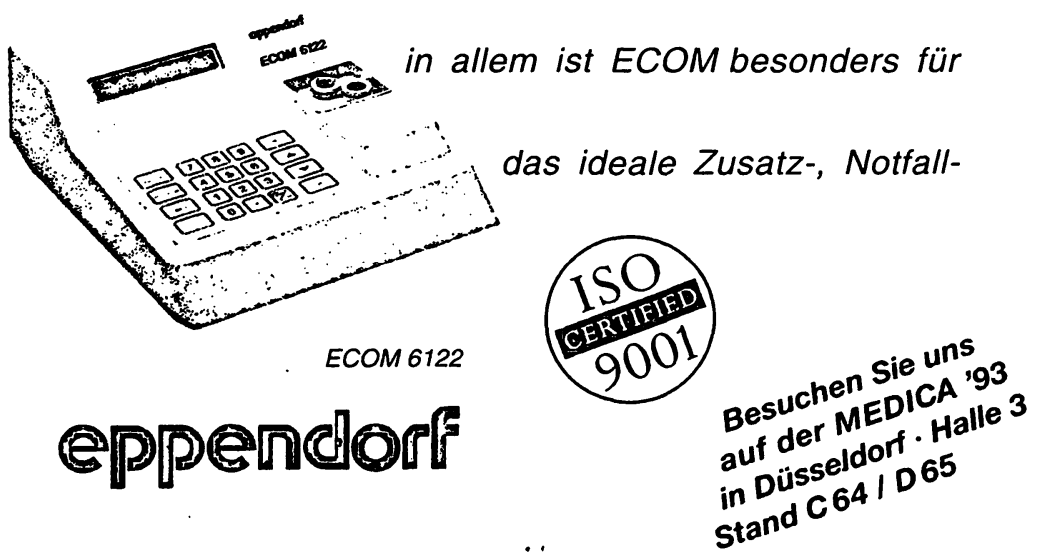

Eppendor - Netheler - Hinz GmbH - D. 22331 Hamburg - Telelon (040) $53801-0$. Telefax (040) $53801556 \cdot$ Teletex-Nr. $403061=$ EGHAA1 


\section{Reaktionsgefäße und mehr - Tischkühlzentrifuge Z $252 \mathrm{MK}$}

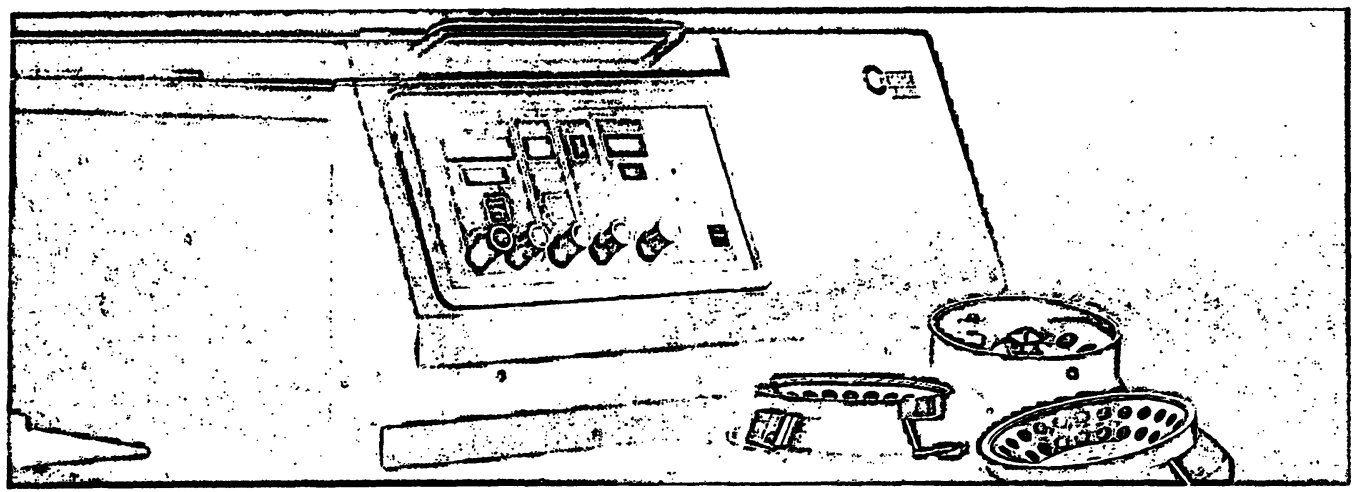

Top-Labortechnih GmbH Gosheimer Straße 56 D-7856+ Wehingen Tel. (07426) 95-4121 Fin (07426) 95-4109 n Das breite Zubehörprogramm macht die „Kleinste“ ganz groß.

Winkelrotor für $12 \times 12 \mathrm{ml}$ Röhrchen bis $\mathrm{zu}$ $15.000 \mathrm{~min}^{-1}$.

Winkelrotor für $24 \times 1,0 \mathrm{ml} / 1,5 \mathrm{ml}$ Reaktionsgefäße bis zu $17.000 \mathrm{~min}^{-1}$.

Winkelrotor für $6 \times 50 \mathrm{ml}$ Falconröhrchen bis zu $6.000 \mathrm{~min}^{-1}$.

Weiteres Zubehör im Prospekt der neuen Hermle Z 252 MK.
- Technik, die überzeugt:

Prozessorgesteuerte Bedienoberfläche mit Soll-/Ist-Wert-Anzeige - wahlweise Anzeige bzw. Vorwahl von Drehzahl oder RZB. Wartungsfreier, bürstenloser Motor.

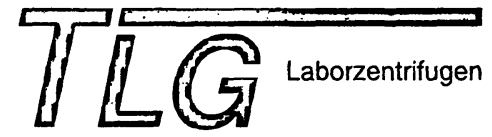

Top-Labortechnik GmbH

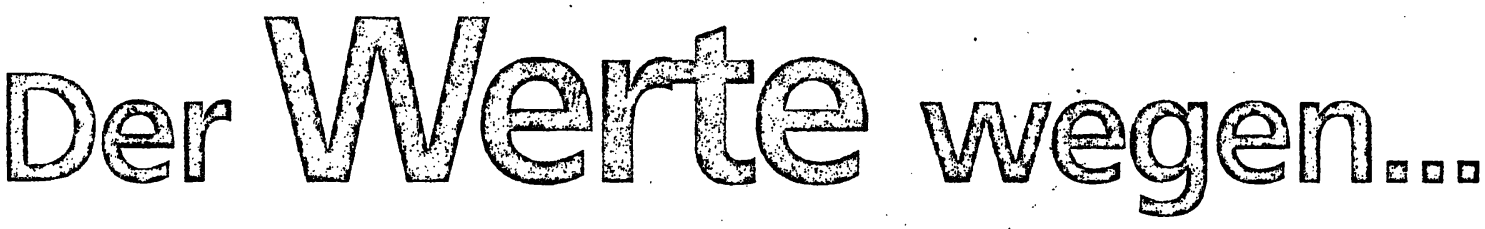

Enzymimmunoassays

Syphilis

H.pylori (lgA, $\lg G)$

Chlamydia trachomatis (lgG)

Rubella* $(\lg G, \lg M)$

EBV $(\lg G, \lg M)$

HSV 1 und 2 (IgG, IgM)

Varizella Zoster Virus. (IgG, IgM)

CMV (IgG)

Masern (IgG, IgM)

Mumps (lgG, $\lg M)$

FSME (IgG, IgM)

Toxoplasmose $(\lg G, \lg M, \lg A)$

Rekombinanter Blot

B. burgdorferi

\section{Hämagglutination}

Syphilis

B. burgdorferi

Rubella

Immunfluoreszenz

Syphilis

B. burgdorferi

Chlamydia trachomatis

HIV $1+2$

Toxoplasmose
Schnelltests

H. pylori

Rubella

Adenovirus

Rotavirus.

IM (Heterophile.Ak)

*zur Zulassung eingereicht

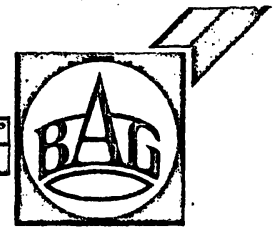

